\title{
Laser remote sensing calibration of ocean color satellite data
}

\author{
Roberto Barbini $\left({ }^{1}\right)$, Francesco Colao $\left({ }^{1}\right)$, Roberta Fantoni $\left({ }^{1}\right)$, Luca Fiorani $\left({ }^{1}\right)$, \\ Natalia V. Kolodnikova $\left({ }^{2}\right)$ and Antonio Palucci $\left({ }^{1}\right)$ \\ (') ENEA, FIS-LAS, Frascati (RM), Italy \\ (2) Tomsk State University of Control Systems and Radioelectronics, Tomsk, Russia
}

\begin{abstract}
One of the main interests of Earth observation is the study of the biogeochemical cycles which take place in the world ocean: in fact, those processes dramatically affect the climatic equilibrium of our planet. For this reason, many advanced active and passive remote sensors have been used to study phytoplankton dynamics, since such phenomena are thought to be responsible for the sequestration of atmospheric carbon dioxide, one of the most important greenhouse gases. In this paper, one laser system and three satellite radiometers routinely used for the study of the phytoplankton dynamics will be briefly reviewed. Satellite sensors have been preferred to airborne sensors because, to our knowledge, ocean color airborne radiometers have not been operated in Antarctica, at least not throughout the whole lapse of time examined in this study. Particular focus was on the laser system (ELF) and on a specific satellite radiometer (SeaWiFS). ELF is based on the laser-induced fluorescence of phytoplankton pigments and was conceived for the Italian expeditions to Antarctica. The goal of SeaWiFS is to provide the Earth science community with quantitative data on the global ocean bio-optical properties. Such satellite radiometer has been calibrated with in situ data mainly acquired in non polar regions. This is why a comparison between ELF and SeaWiFS measurements of chlorophyll-a surface concentrations in the Southern Ocean during the austral summer 1997-1998 was believed to be significant. Our results indicate that SeaWiFS overestimates high concentrations and underestimates low concentrations. In order to correct this behavior, the chlorophyll-a bio-optical algorithm of SeaWiFS has been recalibrated according to the measurements of ELF, thus providing a new estimation of the primary production in the Southern Ocean.
\end{abstract}

Key words LIDAR fluorosensor - satellite radiometer - SeaWiFS calibration - chlorophyll-a primary production - Antarctica

\section{Introduction}

The biogeochemical cycles of the Earth system (Falkowski et al., 2000) play a major role in the climatic equilibrium. Changes in oceanic primary production have profoundly influenced

Mailing address: Dr. Luca Fiorani, ENEA, FIS-LAS, Via Fermi 45, 00044 Frascati (RM), Italy; e-mail: fiorani@frascati.enea.it photosynthetic carbon fixation and, hence, the atmospheric carbon dioxide level for over three billion years (Falkowski et al., 1998a).

Ocean color satellite radiometers (Joint and Groom, 2000) are powerful instruments for the observation of the world ocean: thanks to their unrivalled spatial and time coverage, they provide us with a large amount of data on phytoplankton. Moreover, they can operate continuously for many years, regardless of the frequent bad weather conditions that discouraged the operation of ocean color airborne radiometers in Antarctica: for this reason and taking into account that they are based on the same physical principle, satellite sensors have been preferred to airborne sensors. Also laser remote sensors (Measures, 1992) and, in particular, hydros- 
pheric lidars (Grant, 1995) are now considered to be reliable systems. Unfortunately, ocean color data are not exempt from uncertainties. On the one hand, atmospheric corrections (Fiorani et al., 1998) are necessary to obtain waterleaving radiances by removing from the radiometer measurements the contributions of air molecules and aerosols, which represent up to the $90 \%$ of the total in the visible bands. On the other, the bio-optical algorithms (O'Reilly et al., 1998), i.e. the set of semi-empirical equations used to calculate biogeochemical properties from the water-leaving radiances in the visible bands, are usually calibrated with a limited set of in situ measurements, where polar regions are less represented than temperate regions (Fargion et al., 2003). This could explain why primary production may be misestimated in the Southern Ocean (Arrigo et al., 1998). The important consequences of those studies in making decisions such as setting a fishing quota, justify the efforts to assess ocean color data sensed from space borne radiometers with the «sea truth» provided by ship borne measurements. In this framework, the ENEA LIDAR Fluorosensor (ELF) (Barbini et al., 2001a), operational aboard the Research Vessel (RV) Italica during five oceanographic campaigns gathered a large amount of data useful for the calibration and/or validation of the satellite radiometers.

\section{Instruments and methods}

ELF (fig. 1) excites water through a laser pulse (at $355 \mathrm{~nm}$ ) and observes the Raman backscattering of water (at $404 \mathrm{~nm}$ ) as well as the fluorescence of chlorophyll-a (at $680 \mathrm{~nm}$ ) (Barbini et al., 2001a). The absolute concentration of that pigment is directly proportional to the fluorescence-to-Raman ratio (also known as concentration released in Raman units) (Bris-

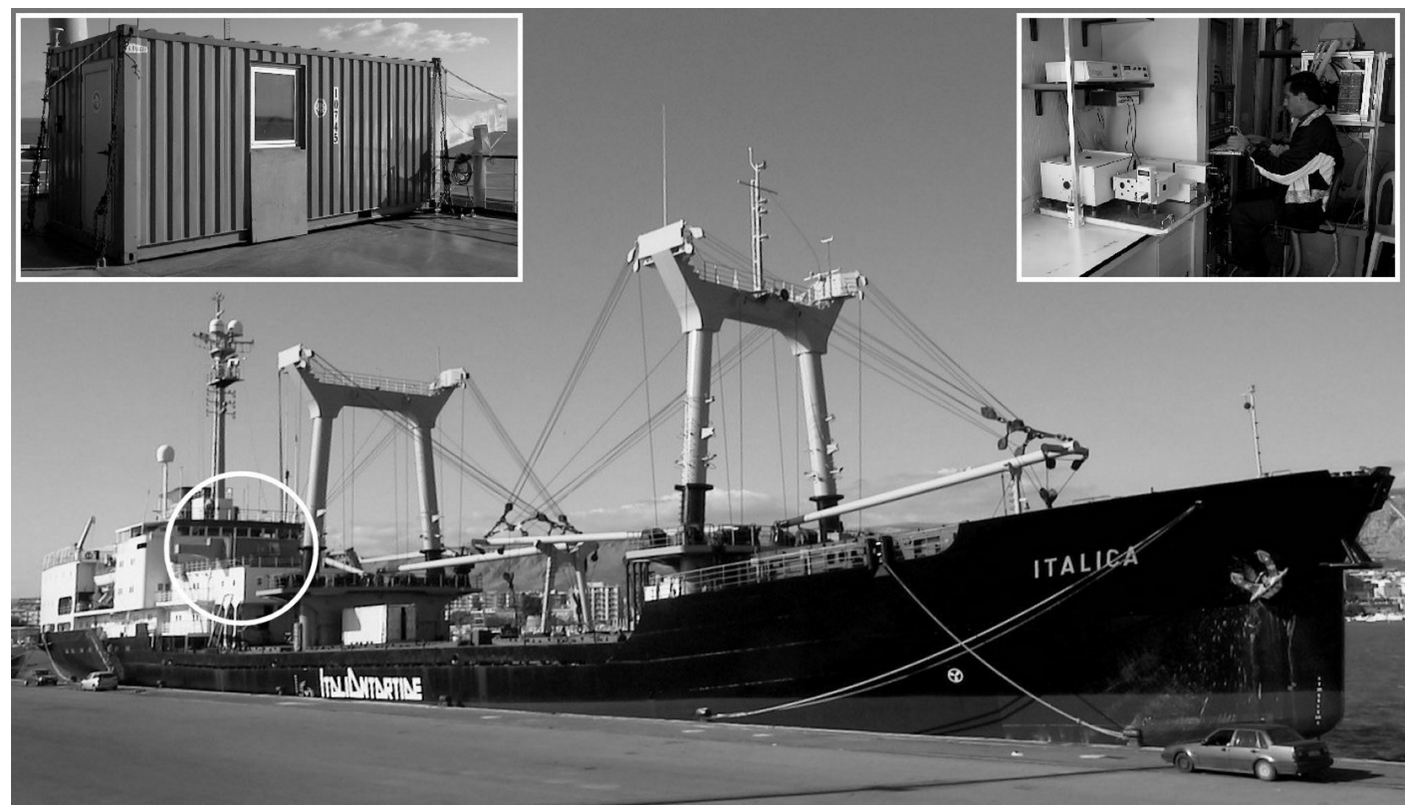

Fig. 1. Main picture: RV Italica; ELF and the ancillary instruments are housed in a container (inside the circle). Left insert: external view of the container; note on the left of the container the box accommodating the mirror for water surface observation. Right insert: internal view of the container; ELF and the spectrofluorometer are visible behind and on the left of the operator, respectively. 
tow et al., 1981; Hoge and Swift, 1981). The Raman units are then converted into $\mathrm{mg} \mathrm{m}^{-3}$, i.e. the absolute concentration is retrieved from the fluorescence-to-Raman ratio, namely by cali-

Table I. Specifications of ELF.

\begin{tabular}{lll}
\hline \hline Transmitter & Laser & Nd:YAG \\
& Wavelength & $355 \mathrm{~nm}$ \\
& $\begin{array}{l}\text { Pulse energy } \\
\text { Pulse duration }\end{array}$ & $3 \mathrm{~mJ}$ \\
& $10 \mathrm{~ns}$ \\
& $\begin{array}{l}\text { Pulse repetition } \\
\text { rate }\end{array}$ & $10 \mathrm{~Hz}$ \\
Receiver & Telescope & Cassegrain \\
& Clear aperture & $0.4 \mathrm{~m}$ \\
& Focal length & $1.65 \mathrm{~m}$ \\
& Center & $404,450,585,680 \mathrm{~nm}$ \\
& wavelengths & \\
& Bandwidths & $5 \mathrm{~nm}$ FWHM \\
Electronics & Detectors & Photomultipliers \\
& Gate width & $100 \mathrm{~ns}$ \\
& $\begin{array}{l}\text { Dynamic range } \\
\text { Bus }\end{array}$ & $15 \mathrm{bit}$ \\
& Central & VME embedded 486 \\
& processing unit & \\
\hline
\end{tabular}

bration against conventional analysis on the same water (Barbini et al., 2001b).

ELF consists mainly of a frequency-tripled Nd:YAG laser (transmitter) and a Cassegrain telescope coupled to detectors (receiver): the laser emits a pulse to the sea surface and the telescope collects the backscattered light at different wavelengths. The radiation is then directed through a fiber bundle to spectral bandpass filters, and is detected with photomultiplier tubes. Other instruments provide ancillary measurements: lamp spectrofluorometer, pulsed amplitude fluorometer, solar radiance detector and global positioning system. The data of lamp spectrofluorometer, pulse amplitude fluorometer and solar radiance detector are not being used in this study. The global positioning system georeferenced the laser measurements. The specifications of ELF are summarized in table I.

The first ocean color radiometer was CZCS (Hovis, 1980), operated on the Nimbus-7 satellite from 1978 to 1986 . Four new ocean color radiometers, SeaWiFS (Hooker et al., 1992), two MODIS sensors (Esaias et al., 1998) and MERIS (Huot et al., 2002), were launched on 1 August 1997, 18 December 1999, 4 May 2002 and 1 March 2002, respectively. The first one, aboard

Table II. Main characteristics of SeaWiFS, MODIS and MERIS.

\begin{tabular}{cccc}
\hline \hline Radiometer & SeaWiFS & MODIS & MERIS \\
\hline Scan width & $\pm 58^{\circ} .3\left(^{\mathrm{a}}\right), \pm 45^{\circ} .0\left(^{\mathrm{b}}\right)$ & $\pm 55^{\circ}$ & $\pm 34^{\circ} .25$ \\
Scan coverage & $2.800 \mathrm{~km}\left({ }^{\mathrm{a}}\right), 1.500 \mathrm{~km}\left({ }^{\mathrm{b}}\right)$ & $2.330 \mathrm{~km}$ & $1.150 \mathrm{~km}$ \\
Nadir resolution & $1.13 \mathrm{~km}\left({ }^{\mathrm{a}}\right), 4.5 \mathrm{~km}\left(^{\mathrm{b}}\right)$ & $0.25 \mathrm{~km}\left({ }^{\mathrm{c}}\right), 0.5 \mathrm{~km}\left({ }^{\mathrm{d}}\right), 1 \mathrm{~km}\left(^{\mathrm{e}}\right)$ & $0.3 \mathrm{~km}\left({ }^{\mathrm{f}}\right), 1.2 \mathrm{~km}\left(^{\mathrm{g}}\right)$ \\
Bands & $8(412-865 \mathrm{~nm})$ & $36(405-14.385 \mathrm{~nm})$ & $15(412.5-900 \mathrm{~nm})$ \\
Scan period & $0.167 \mathrm{~s}\left(^{\mathrm{h}}\right)$ & $0.903 \mathrm{~s}\left({ }^{\mathrm{h}}\right)$ & $0.044 \mathrm{~s}\left(^{\mathrm{i}}\right)$ \\
Tilt & $20^{\circ}, 0^{\circ},+20^{\circ}$ & No & No \\
Digitization & $10 \mathrm{bits}$ & 12 bits & $12 \mathrm{bits}$ \\
Acquisition & 4 September 1997 & 24 February $2000\left(^{\mathrm{j}}\right)$ & 22 March 2002 \\
\hline
\end{tabular}

( ${ }^{\mathrm{a}}$ Local area coverage.

(b) Global area coverage.

( ${ }^{c}$ ) Bands 1-2.

(d) Bands 3-7.

( $)$ Bands 8-36.

(5) Full resolution.

$\left({ }^{g}\right)$ Reduced resolution.

( $\left.{ }^{\mathrm{h}}\right)$ From the period of the continuously rotating scan mirror.

(i) From the period of the CCD frame.

$\left({ }^{j}\right)$ For MODIS aboard Terra; 24 June 2002 for MODIS aboard Aqua. 
OrbView-2, is a joint venture of Orbital Sciences Corporation and the National Aeronautics and Space Administration (NASA). The two MODIS sensors, integrated on Terra and Aqua, respectively, are part of the NASA's Earth Observing System (EOS), a program including six spacecrafts: Aqua, Aura, ICESat, Landsat 7, SORCE and Terra. MERIS is one of the instruments aboard ENVISAT, the most important Earth observing satellite of the European Space Agency (ESA).

The modern ocean color radiometers have been mainly designed for the observation of the phytoplankton biochemistry: in particular, they are expected to provide surface chlorophyll-a concentration over the range 0.05 to $50 \mathrm{mg} \mathrm{m}^{-3}$ with an absolute accuracy of $35 \%$. The main characteristics of SeaWiFS, MODIS and MERIS are summarized in table II.

\section{Results and discussions}

ELF participated in four Italian expeditions to Antarctica (13th, 15th, 16th and 18th in 19971998, 2000, 2001 and 2003, respectively) (Barbini et al., 2001a) as well as in the MIPOT (Mediterranean Sea, Indian and Pacific Oceans Transect) oceanographic campaign (2001-2002) (Barbini et al., 2004a). Up to now the comparison between laser and satellite data for the 13th expedition (Barbini et al., 2003a) has been investigated more thoroughly: this is why the calibration of SeaWiFS by ELF during the 13th expedition will be described here as a case study.

ELF data were compared with 8-day L3 SeaWiFS data products. The 8-day time interval permitted us to gather enough simultaneous measurements and the L3 processing level ensured the highest accuracy. Although these choices involved a rather poor granularity ( 8 days in time, about $9 \mathrm{~km} \times 9 \mathrm{~km}$ in space), they have been considered to be the best compromise. The resolution of ELF is very different, since a laser pulse is emitted every $0.1 \mathrm{~s}$ and its footprint on the water surface sizes around 0.1 m. In order to compare the data, all the ELF measurements falling in a SeaWiFS pixel were averaged, thus representing a track (length: $\sim 10$ $\mathrm{km}$, width: $\sim 0.1 \mathrm{~m}$ ) acquired in about $1 \mathrm{~h}$. The remaining dissimilarity in granularity can hard- ly be avoided and may be responsible for part of the differences between SeaWiFS and ELF. Anyhow, the overall agreement between SeaWiFS and ELF was estimated to be satisfactory (Barbini et al., 2003a).

During the 13th expedition, ELF measured surface chlorophyll-a concentrations in the Ross Sea and the Antarctica-New Zealand transect (Barbini et al., 2003a). The RV Italica left Terra Nova Bay on 7 December 1997 and arrived to New Zealand on 14 January 1998. From the trophic point of view, the study area contained two main regions: the first (Ross Sea) is more productive (chlorophyll-a up to $9 \mathrm{mg} \mathrm{m}^{-3}$ ) and the second (Antarctica-New Zealand transect) is less productive (chlorophyll-a up to $2 \mathrm{mg} \mathrm{m}^{-3}$ ).

The direct comparison between ELF and SeaWiFS chlorophyll-a concentrations (fig. 2) shows that SeaWiFS overestimate high concentrations (characteristics of the waters crossed during the second 8-day period) and underestimates the low concentrations (typical of the Ross Sea-New Zealand transect covered during the last 8-day period).

Bio-optical algorithms can be separated into two main classes: semianalytical and empirical ones. An evaluation of 2 semianalytical and 15 empirical algorithms based on a large set of radiance and chlorophyll-a data, demonstrated the better performances of the empirical algorithms and provided the parameters of the equations used to calculate chlorophyll-a concentrations from the water-leaving radiances ( $\mathrm{O}$ 'Reilly et al., 1998). Unfortunately, most of those observations were from Case I non polar waters (McClain et al., 2000a,b; O'Reilly et al., 2000), thus such parameters should be applied cautiously to the Southern Ocean. In the following, the SeaWiFS chlorophyll-a algorithm is calibrated for the Ross Sea on the basis of the ELF measurements taken during the 13th expedition (Barbini et al., 2003a). In other words, the parameters of the semi-empirical equations used to calculate the chlorophyll-a concentrations are obtained from fits on the ship observations and used to calculate the chlorophyll-a concentrations from the water-leaving radiances.

While the SeaWiFS output is the normalized water-leaving radiance (Lwn), the empirical algorithms input is usually the remote sens- 


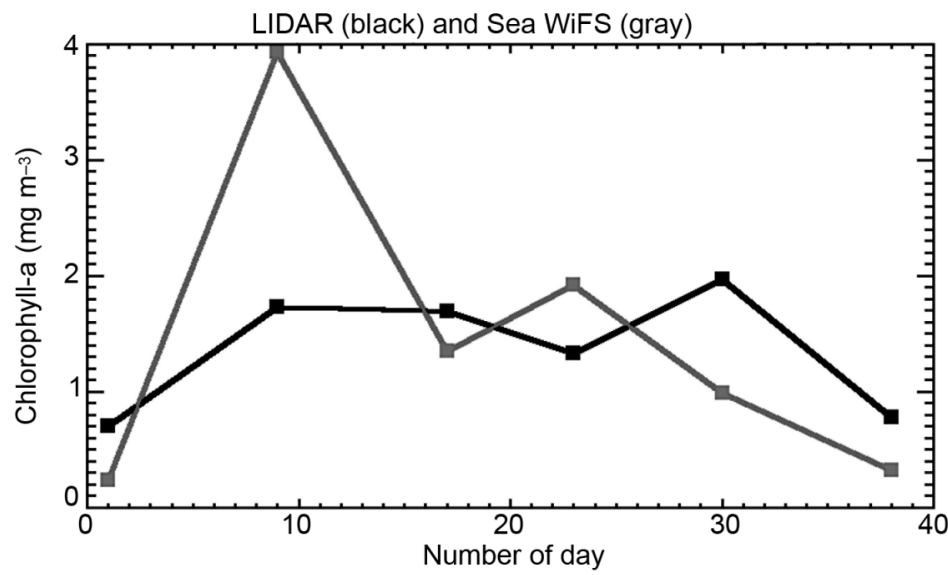

Fig. 2. Surface chlorophyll-a concentration measured by ELF (black), SeaWiFS (gray) as a function of the number of day from the beginning of the 13th Italian expedition to Antarctica (the points correspond to the 8day periods of the SeaWiFS data products).

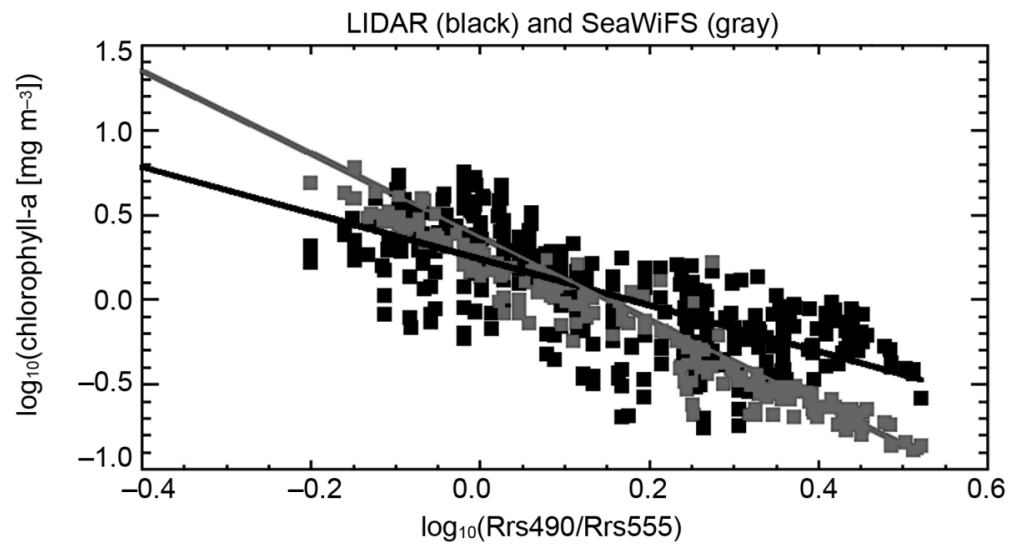

Fig. 3. ELF (black squares) and standard SeaWiFS (gray squares) chlorophyll-a concentration versus SeaWiFS band ratio. The black and gray lines correspond to ELF-calibrated OC1 and standard OC1 bio-optical algorithms, respectively. The standard SeaWiFS chlorophyll-a concentration versus SeaWiFS band ratio represents the OC4 bio-optical algorithm.

ing reflectance (Rrs) (O'Reilly et al., 1998). Their relation is given by

$$
\operatorname{Lwn}(\lambda)=F_{0}(\lambda) \operatorname{Rrs}(\lambda)
$$

where $\lambda$ is the wavelength and $F_{0}$ is the mean extraterrestrial solar irradiance. The simplest algorithm (OC1) is expressed by (O'Reilly et al., 1998)

$$
C=10^{a_{0}+a_{1} R}
$$

where $C$ is the chlorophyll-a concentration in $\mathrm{mg} \mathrm{m}^{-3}$ and

$$
R=\log _{10} \frac{\operatorname{Rrs}(490 \mathrm{~nm})}{\operatorname{Rrs}(555 \mathrm{~nm})}
$$

While a modified cubic polynomial function (OC2) (O'Reilly et al., 1998) 


$$
C=10^{a_{0}+a_{1} R+a_{2} R^{2}+a_{3} R^{3}}+a_{4}
$$

has been chosen as at-launch SeaWiFS operational algorithm, a maximum band ratio method (OC4) (O'Reilly et al., 1998) gives the best results and is being used at present. In OC4, C is computed as in eq. (3.4), but the ratio of formula (3.3) is whichever ratio, among $\operatorname{Rrs}(443$ $\mathrm{nm}) / \operatorname{Rrs}(555 \mathrm{~nm})$ or $\operatorname{Rrs}(490 \mathrm{~nm}) / \operatorname{Rrs}(555 \mathrm{~nm})$ or $\operatorname{Rrs}(510 \mathrm{~nm}) / \operatorname{Rrs}(555 \mathrm{~nm})$, results to be the highest. In this way, one of the two other ratios replaces $\operatorname{Rrs}(490 \mathrm{~nm}) / \operatorname{Rrs}(555 \mathrm{~nm})$ when the latter is low and noisy. $\operatorname{Rrs}(443 \mathrm{~nm}) / \operatorname{Rrs}(555 \mathrm{~nm})$ is usually employed for $\mathrm{C}$ lower than about 0.3 $\mathrm{mg} \mathrm{m}^{-3}, \operatorname{Rrs}(510 \mathrm{~nm}) / \operatorname{Rrs}(555 \mathrm{~nm})$ for $C$ higher than about $1.5 \mathrm{mg} \mathrm{m}^{-3}$. The switching between $\operatorname{Rrs}(490 \mathrm{~nm}) / \operatorname{Rrs}(555 \mathrm{~nm}), \operatorname{Rrs}(443 \mathrm{~nm}) / \operatorname{Rrs}$ $(555 \mathrm{~nm})$ and $\operatorname{Rrs}(510 \mathrm{~nm}) / \operatorname{Rrs}(555 \mathrm{~nm})$ explains the dispersion of SeaWiFS chlorophyll-a concentrations versus SeaWiFS band ratios.

Figure 3 shows a large dispersion of the ELF points. Consequently, the linear fit (OC1) has been chosen. As in previous regional calibrations (Mitchell and Holm-Hansen, 1991; Mitchell, 1992), it does not seem reasonable to use any higher order functions, given the unstable behavior of the corresponding fits. Figure 3 also displays the ELF-calibrated OC1 and standard OC1 bio-optical algorithms, as well as standard SeaWiFS chlorophyll-a concentrations (representing the OC4 bio-optical algorithm) versus SeaWiFS band ratios, thus confirming that the standard algorithm overestimates high concentrations (more than about $1 \mathrm{mg} \mathrm{m}^{-3}$ ) and underestimates low concentrations.

The present results have been obtained with 523 experimental points collected in the Ross Sea sector of the Southern Ocean in the period from 7 December 1997 to 14 January 1998 (13th expedition). Spatial zone and time interval correspond to a nearly homogeneous biological sample, which is representative of Antarctic phytoplankton (Barbini et al., 2004b). If one examines the data of the 16th expedition (1658 experimental points) (Colao et al., 2005), it is confirmed that the standard algorithm overestimates high concentrations and underestimates low concentrations (fig. 4). To be noted that the difference between the OC1 algorithms calibrated with the data of 13th and 16th expeditions is smaller than the dispersion of the ELF points, i.e. the two algorithms agree within the statistical fluctuation. In the following, the OC1 algorithm calibrated with the data of the 13th

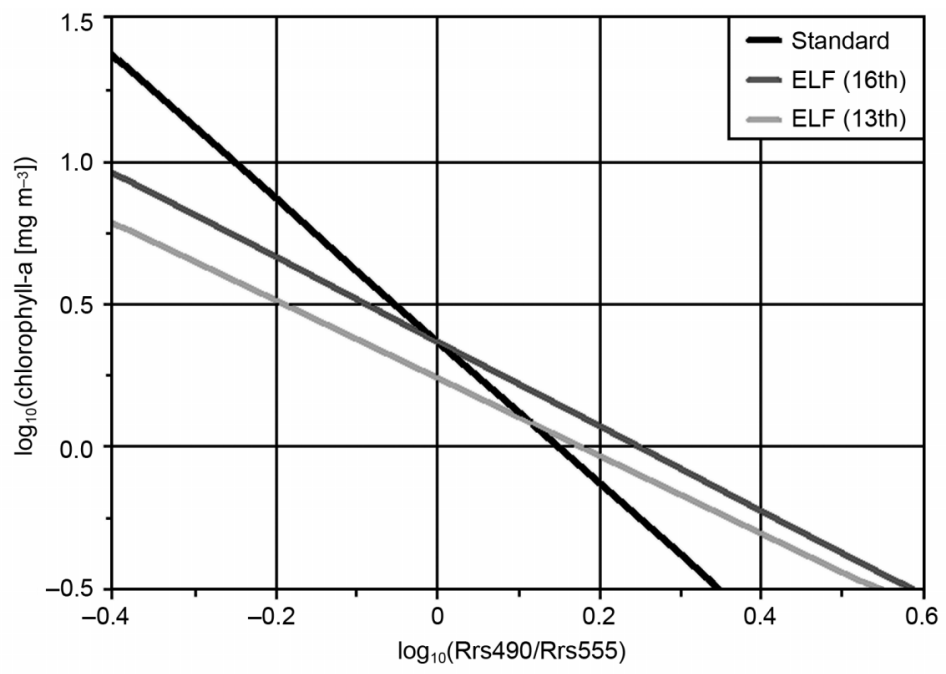

Fig. 4. Comparison among different $\mathrm{OC} 1$ bio-optical algorithms: standard (black) and calibrated with ELF during the 16th (dark gray) and 13th campaign (light gray). 

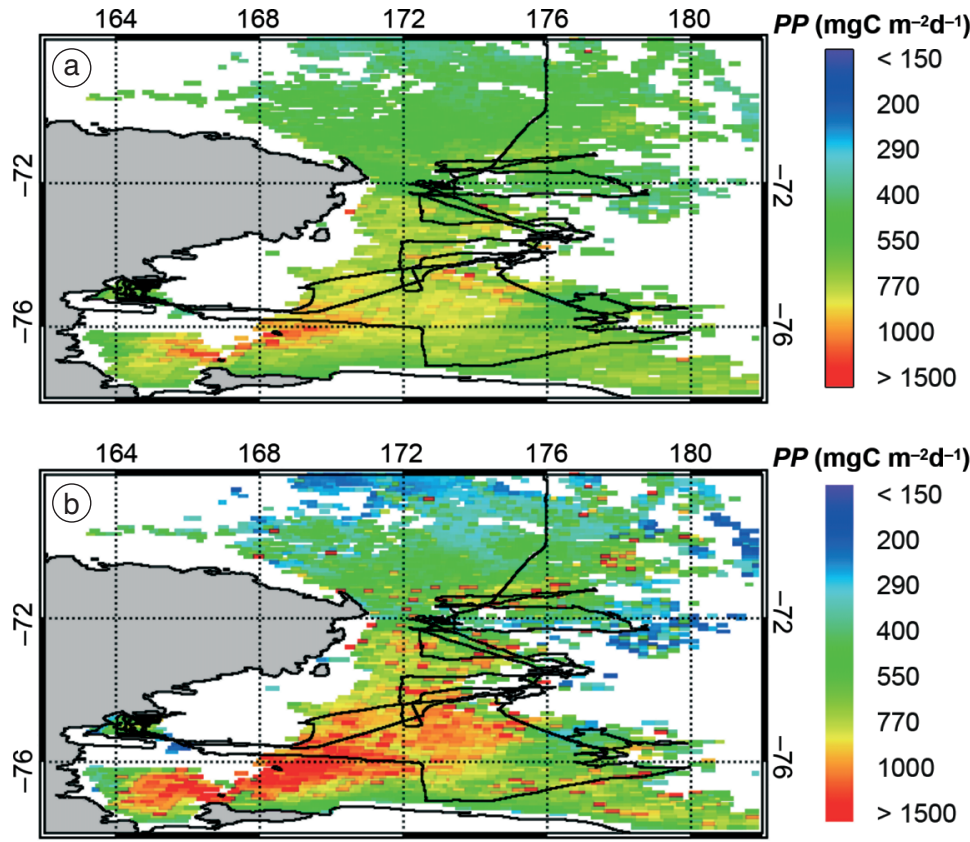

Fig. 5a,b. ELF-calibrated (a) and standard (b) SeaWiFS primary production in the Western Ross Sea in the period from 3 December 1997 to 16 January 1998. Gray area: land; white area: sea; black thick line: ship track.

expedition will be used because the austral summer 1997-1998 was investigated.

Once the chlorophyll-a bio-optical algorithm is assessed, its results can be used for the calculation of the primary production (Barbini et al., 2003b), e.g., according to the standard NASA's model (Falkowski et al., 1998b)

$$
\log _{10} P P=2.793+0.559 \log _{10} C
$$

where $P P$ is the daily depth-integrated primary

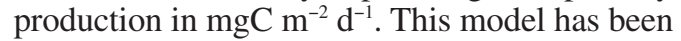
chosen because it represents a sort of consensus algorithm for SeaWiFS. Primary production maps, both with and without ELF calibration, are plotted in fig. 5a,b for the Western Ross Sea in the time interval starting on 3 December 1997 and ending on 16 January 1998 . This period has been selected in order to match radiometer products with LIDAR measurements. Areas in white had no data due to cloud or ice cover. The discrepancy between standard and ELF-calibrated

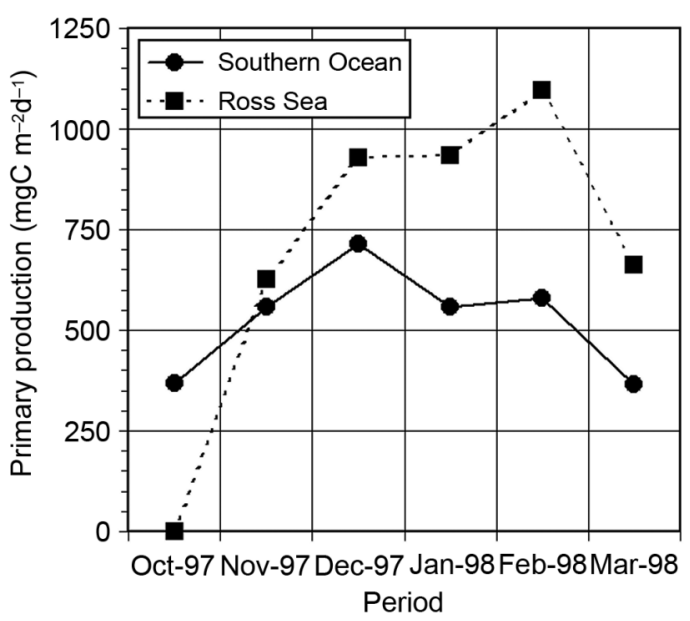

Fig. 6. ELF-calibrated SeaWiFS primary production in the Southern Ocean (Longitude: $157^{\circ} .5-180^{\circ}$; Latitude: $\left.-61^{\circ} .875-78^{\circ} .75\right)$ and in the Ross Sea (Longitude: $157^{\circ} .5-180^{\circ}$; Latitude: $-72^{\circ} .07--78^{\circ} .75$ ) during the austral summer 1997-1998. 
primary production parallels that of standard and ELF-calibrated chlorophyll-a: SeaWiFS values are larger and smaller for high and low primary productions, respectively. In both cases, a phytoplankton bloom filling the open sea located northeast of the Ross Island is to be noted: the maximum productivity exceeds 1000 $\mathrm{mgC} \mathrm{m} \mathrm{m}^{-2} \mathrm{~d}^{-1}$. The ELF-calibrated bio-optical algorithm has also been applied to the entire austral summer 1997-1998 by using monthly averaged SeaWiFS products in two regions: the first one only covers the Western Ross Sea (Longitude: $157^{\circ} .5-180^{\circ}$; Latitude: $\left.-72^{\circ} .07--78^{\circ} .75\right)$ and the second one extends to the Southern Ocean (Longitude: $157^{\circ} .5-180^{\circ}$; Latitude: $\left.-61^{\circ} .875--78^{\circ} .75\right)$. These data (fig. 6) confirm that, near Antarctic coasts, the dynamics of phytoplankton blooms is faster than in the open ocean (note the steady increase in primary production in the smaller area from October to November 1997): the polynya formed after ice melting is dominated by prompt algal outgrowths, largely driven by environmental conditions such as formation of high salinity shelf waters, pressure, temperature, available solar radiation and katabatic winds. The primary production is larger if the clorophyll-a algorithm is calibrated with ELF: the average difference in the Ross Sea and the Southern Ocean regions defined above is about 10 and $20 \%$, respectively. This result, could contribute to the solution of the «Antarctic paradox», an unexpected behavior that can be stated as follows: the primary production of Antarctic waters seems to be insufficient to support the population of grazers (Arrigo et al., 1998).

\section{Conclusions}

The remote sensing data provided by a laser system (ELF) and a satellite radiometer (SeaWiFS) have been compared. Moreover, the «sea truth» provided by the laser system has been used to calibrate the imagery gathered by the satellite radiometer. In this way, we combined active and passive remote sensing, thus merging their advantages (accuracy of ELF and coverage of SeaWiFS).

In other words, the SeaWiFS chlorophyll-a bio-optical algorithm has been tuned in the
Southern Ocean with the ELF measurements. Our findings indicate that the standard algorithm overestimates high concentrations and underestimates low concentrations. The ELFcalibrated data have been used for a new estimation of the primary production. Once applied this new calculation in the Southern Ocean, we found that average primary production is usually underestimated. Those results indicate that this regional algorithm could give useful estimates of primary production in the Antarctic seawaters. In particular, it could help in overcoming the «Antarctic paradox».

\section{Acknowledgements}

Special acknowledgments are addressed to S. Fonda Umani et al. and V. Saggiomo et al. for kindly providing unpublished data. This work has been supported by the Italian Antarctic Research Program (PNRA), Technology Sector, 5b1 Lidar Fluorosensor and 11-5 Palucc5 Projects (for the periods 1996-1998 and 1999-2001, respectively). The authors would like to thank the SeaWiFS Project (Code 970.2) and the Distributed Active Archive Center (Code 902) at the Goddard Space Flight Center, Greenbelt, MD 20771, for the production and distribution of these data, respectively. These activities are sponsored by NASA's Mission to Planet Earth Program.

\section{REFERENCES}

Arrigo, K.R., D. L. Worthen, A. Schnell and M.P. LiZOTTE (1998): Primary production in Southern Ocean waters, J. Geophys. Res., 103 (C8), 15587-15600.

Barbini, R., F. Colao, R. Fantoni, L. Fiorani and A. PALUCCI (2001a): Remote sensing of the Southern Ocean: techniques and results, J. Optoelectron. Adv. Mater., 3, 817-830

Barbini, R., F. Colao, R. Fantoni, A. Palucci and S. RiBEzzo (2001b): Differential LIDAR fluorosensor system used for phytoplankton bloom and seawater quality monitoring in Antarctica, Int. J. Remote Sensing, 22 (2-3), 369-384.

Barbini, R., F. ColaO, R. Fantoni, L. Fiorani and A. PALUCCI (2003a): Lidar fluorosensor calibration of the SeaWiFS chlorophyll algorithm in the Ross Sea, Int. J. Remote Sensing, 24 (16), 3205-3218, doi: 10.1080/ /0143116021000047938.

Barbini, R., F. ColaO, R. Fantoni, L. Fiorani and A. 
PALUCCI (2003b): Remote sensed primary production in the Western Ross Sea: results of in situ tuned models, Antarct. Sci., 15, 77-84.

Barbini, R., F. Colao, L. De Dominicis, R. Fantoni, L. Fiorani, A. Palucci and E.S. Artamonov (2004a): Analysis of simultaneous chlorophyll measurements by LIDAR fluorosensor, MODIS and SeaWiFS, Int. J. Remote Sensing, 25 (11), 2095-2110 doi: 10.1080/ /01431160310001618086.

Barbini, R., M. Cabrini, F. Colao, R. Fantoni, L. Fiorani, S. Fonda Umani, N. Kolodnikova, L. Lazzara, A. PAlucCi and F. PARMiggiani (2004b): Biochemical structure and properties of the Ross Sea during the Austral summer 1997-1998, in XXVIII SCAR and COMNAP XVI, AWS, Berlin, Germany.

Bristow, M.R., D. Nielsen, D. Bundy and R. Furtek (1981): Use of water Raman emission to correct airborne laser fluorosensor data for effects of water optical attenuation, Appl. Opt., 20, 2889-2906.

Colao, F., R. Fantoni, L. Fiorani, A. Palucci and I.G. OKLADNIKOV (2005): Lidar and satellite observations of the Southern Ocean, ENEA Tech. Rep. Ser. RT/2004/65FIS (ENEA, Frascati).

Esaias, W.E., M.R. AbbotT, I. Barton, O.B. Brown, J.W. Campbell, K.L. Carder, D.K. Clark, R.H. Evans, F.E. Hoge, H.R. Gordon, W.M. BALCh, R. Letelier and P.J. MinNETT (1998): An overview of MODIS capabilities for ocean science observations, IEEE Trans. Geosci. Remote Sensing, 36, 1250-1265.

FAlkowski, P.G., R.T. BARBER and V. SMetaceK (1998a): Biogeochemical controls and feedbacks on ocean primary production, Science, 281, 200-206.

Falkowski, P.G., M.J. Behrenfeld, W.E. Esaias, W. Balch, J.W. Campbell, R.L. Iverson, D.A. Kiefer, A. Morel and J.A. Yoder (1998b): Satellite primary productivity data and algorithm development: A science plan for Mission to the Planet Earth, in SeaWiFS Technical Report Series - NASA Technical Memorandum 104566, edited by S.B. HoOKER and E.R. FIRESTONE (NASA, Greenbelt), 42, 1-36.

Falkowski, P.G., R. J. Scholes, E. Boyle, J. Canadell, D. Canfield, J. Elser, N. Gruber, K. Hibbard, P. HögBerg, S. Linder, F.T. Mackenzie, B. Moore III, T. Pedersen, Y. Rosenthal, S. Seitzinger, V. SmetaceK and W. STEFFEN (2000): The global carbon cycle: a test of our knowledge of Earth as a system, Science, 290, 291-296.

Fargion, G., B. Franz, E. Kwiatkowska, C. Pietras, S. Bailey, J. Gales, G. Meister, K. Knobelspiesse, J. WERDELL and C. MCCLAIN (2003): SIMBIOS program in support of ocean color missions: 1997-2003, SPIE Proc., 5155, 49-60.

Fiorani, L., S. MatteI and S. Vetrella (1998): Laser methods for the atmospheric correction of marine radiance data sensed from satellite, SPIE Proc., 3496, 176-187.

Grant, W.B. (1995): Lidar for atmospheric and hydrospheric studies, in Tunable Laser Applications, edited by F.J. DuARTE (Marcel Dekker, New York), 213-305.

Hoge, F.E. and R.N. SwIFT (1981): Airborne simultaneous spectroscopic detection of laser-induced water Raman backscatter and fluorescence from chlorophyll $a$ and other naturally occurring pigments, Appl. Opt., 20, 3197-3205.

Hooker, S.B., W.E. Esaias, G.C. Feldman, W.W. GregG and C.R. McClain (1992): An overview of SeaWiFS and ocean color, in SeaWiFS Technical Report Series NASA Technical Memorandum 104566, edited by S.B. HoOKer and E.R. FIRESTONE (NASA, Greenbelt), 1, $1-25$.

Hovis, W.A. (1980): Nimbus-7 coastal zone color scanner: system description and initial imagery, Science, $\mathbf{2 1 0}$, 60-63.

Huot, J.-P., H. Tait, M. Rast, S. Delwart, J.-L. Bézy and G. LEVRINI (2002): The optical imaging instruments and their applications: AATSR and MERIS, ESA Bull., 106, 56-66.

JoINT, I. and S.B. Groom (2000): Estimation of phytoplankton production from space: current status and future potential of satellite remote sensing, J. Exper. Mar. Biol. Ecol., 250, 233-255.

McClain, C.R., E.J. Ainsworth, R.A. BARnes, R.E. EpleE JR., F.S. PATT, W.D. Robinson, M. WANG and S.W. BAILEY (2000a): SeaWiFS Postlaunch Calibration and Validation Analyses, Part 1, NASA Technical Memorandum 2000-206892, edited by S.B. HoOKER and E.R. FIRESTONE (NASA, Greenbelt), 9, pp. 82.

McClain, C.R., R.A. Barnes, R.E. Eplee Jr., B.A. Franz, N.C. Hsu, F.S. Patt, C.M. Pietras, W.D. Robinson, B.D. Schieber, G.M. Schmidt, M. WANG, S.W. BAIley and P.J. Werdell (2000b): SeaWiFS Postlaunch Calibration and Validation Analyses, Part 2. NASA Technical Memorandum 2000-206892, edited by S.B. HooKER and E.R. FIRESTONE (NASA, Greenbelt), 10, pp. 57.

Measures, R.M. (1992): Laser Remote Sensing (Krieger Publishing Company, Malabar), pp. 510.

Mitchell, B.G. (1992): Predictive bio-optical relationships for polar oceans and marginal ice zones, J. Mar. Sys., 3, 91-105.

Mitchell, B.G. and O. Holm-Hansen (1991): Bio-optical properties of Antarctic Peninsula waters: Differentiation from temperate ocean models, Deep Sea Res., Part A, 38, 1009-1028.

O’Reilly, J.E., S. Maritorena, B.G. Mitchell, D.A. Siegel, K.L. Carder, S.A. Garver, M. Kahru and C. MCCLAIN (1998): Ocean color chlorophyll algorithms for SeaWiFS, J. Geophys. Res., 103 (C11), 2493724953.

O'Reilly, J.E., S. Maritorena, M.C. O'Brien, D.A. Siegel, D. Toole, D. Menzies, R.C. Smith, J.L. Mueller, B. Greg Mitchell, M. Kahru, F.P. Chavez, P. Strutton, G.F. Cota, S.B. Hooker, C.R. McClain, K.L. Carder, F. Müller-Karger, L. Harding, A. Magnuson, D. Phinney, G.F. Moore, J. Aiken, K.R. Arrigo, R. Letelier and M. Culver (2000): SeaWiFS Postlaunch Calibration and Validation Analyses, Part 3. NASA Technical Memorandum 2000-206892, edited by S.B. HoOKer and E.R. FIRESTONE (NASA, Greenbelt), 11, pp. 49. 